\begin{tabular}{|c|c|}
\hline Title & Origin of positive fixed charge at insulator/A IGaN interfaces and its control by AIGaN composition \\
\hline Author(s) & Matys, M.; Stoklas, R.; Blaho, M.; A damowicz, B. \\
\hline Citation & $\begin{array}{l}\text { A pplied physics letters, } 110(24), 243505 \\
\text { https://doi.org/10.1063/1.4986482 }\end{array}$ \\
\hline Issue Date & 2017-06-15 \\
\hline Doc URL & http:/hdl.handle.net/2115/70734 \\
\hline Rights & $\begin{array}{l}\text { This article may be downloaded for personal use only. A ny other use requires prior permission of the author and A IP } \\
\text { Publishing.T he following article appeared in A pplied Physics Letters, } 243505 \text { (2017) and may be found at } \\
\text { http://aip.scitation.org/doi } / 10.1063 / 1.4986482 \text {. }\end{array}$ \\
\hline Type & article \\
\hline File Information & 1.4986482.pdf \\
\hline
\end{tabular}

Instructions for use 


\section{Origin of positive fixed charge at insulator/AIGaN interfaces and its control by AIGaN composition}

M. Matys, R. Stoklas, M. Blaho, and B. Adamowicz

Citation: Appl. Phys. Lett. 110, 243505 (2017); doi: 10.1063/1.4986482

View online: https://doi.org/10.1063/1.4986482

View Table of Contents: http://aip.scitation.org/toc/apl/110/24

Published by the American Institute of Physics

\section{Articles you may be interested in}

Trap state analysis in AIGaN/GaN/AIGaN double heterostructure high electron mobility transistors at high temperatures

Applied Physics Letters 110, 252102 (2017); 10.1063/1.4986776

Improved interface properties of GaN-based metal-oxide-semiconductor devices with thin Ga-oxide interlayers Applied Physics Letters 110, 261603 (2017); 10.1063/1.4990689

Thickness engineering of atomic layer deposited $\mathrm{Al}_{2} \mathrm{O}_{3}$ films to suppress interfacial reaction and diffusion of $\mathrm{Ni} /$ Au gate metal in AIGaN/GaN HEMTs up to $600^{\circ} \mathrm{C}$ in air

Applied Physics Letters 110, 253505 (2017); 10.1063/1.4986910

Design and control of interface reaction between Al-based dielectrics and AIGaN layer in AIGaN/GaN metaloxide-semiconductor structures

Applied Physics Letters 111, 042102 (2017); 10.1063/1.4986419

On the physical operation and optimization of the $p-G a N$ gate in normally-off GaN HEMT devices

Applied Physics Letters 110, 123502 (2017); 10.1063/1.4978690

On the origin of interface states at oxide/III-nitride heterojunction interfaces

Journal of Applied Physics 120, 225305 (2016); 10.1063/1.4971409

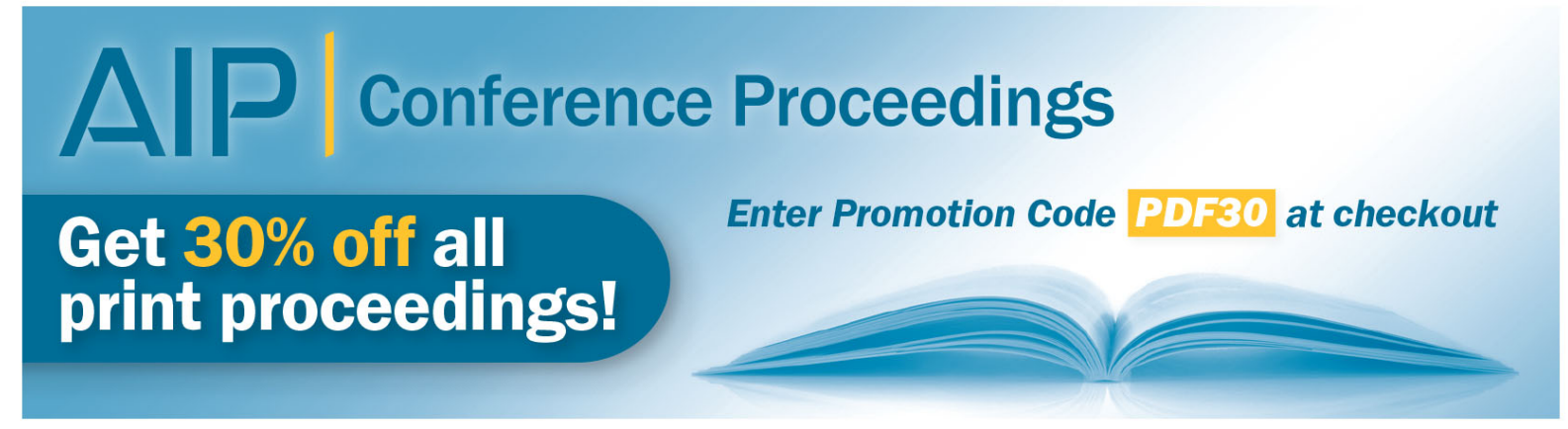




\title{
Origin of positive fixed charge at insulator/AIGaN interfaces and its control by AIGaN composition
}

\author{
M. Matys, ${ }^{1,2}$ R. Stoklas, ${ }^{3}$ M. Blaho, ${ }^{3}$ and B. Adamowicz ${ }^{2}$ \\ ${ }^{1}$ Research Center for Integrated Quantum Electronics, Hokkaido University, Kita-13 Nishi-8, Kita-ku, \\ 060-8628 Sapporo, Japan \\ ${ }^{2}$ Surface Physics and Nanostructures Department, Institute of Physics - CSE, Silesian University \\ of Technology, Konarskiego 22B, 44-100 Gliwice, Poland \\ ${ }^{3}$ Institute of Electrical Engineering, Slovak Academy of Sciences, Dubravska cesta 9 , \\ 84104 Bratislava, Slovak Republic
}

(Received 10 March 2017; accepted 5 June 2017; published online 15 June 2017)

\begin{abstract}
The key feature for the precise tuning of $V_{t h}$ in GaN-based metal-insulator-semiconductor (MIS) high electron mobility transistors is the control of the positive fixed charge $\left(Q_{f}\right)$ at the insulator/III$\mathrm{N}$ interfaces, whose amount is often comparable to the negative surface polarization charge $\left(Q_{\text {pol }}^{-}\right)$. In order to clarify the origin of $Q_{f}$, we carried out a comprehensive capacitance-voltage $(\mathrm{C}-\mathrm{V})$ characterization of $\mathrm{SiO}_{2} / \mathrm{Al}_{x} \mathrm{Ga}_{1-x} \mathrm{~N} / \mathrm{GaN}$ and $\mathrm{SiN} / \mathrm{Al}_{x} \mathrm{Ga}_{1-x} \mathrm{~N} / \mathrm{GaN}$ structures with $\mathrm{Al}$ composition (x) varying from 0.15 to 0.4 . For both types of structures, we observed a significant $V_{t h}$ shift in $\mathrm{C}-\mathrm{V}$ curves towards the positive gate voltage with increasing $\mathrm{x}$. On the contrary, the Schottky gate structures exhibited $V_{t h}$ shift towards the more negative biases. From the numerical simulations of $\mathrm{C}-\mathrm{V}$ curves using the Poisson's equation supported by the analytical calculations of $V_{t h}$, we showed that the $V_{t h}$ shift in the examined MIS structures is due to a significant decrease in the positive $Q_{f}$ with rising $\mathrm{x}$. Finally, we examined this result with respect to various hypotheses developed in the literature to explain the origin of the positive $Q_{f}$ at insulator/III-N interfaces. Published by AIP Publishing. [http://dx.doi.org/10.1063/1.4986482]
\end{abstract}

GaN-based metal-insulator-semiconductor high electron mobility transistors (MISHEMTs) become very attractive for applications in energy-efficient power switching devices. ${ }^{1-10}$ However, achieving normally-off or enhancement mode transistors with the positive threshold voltage $\left(V_{t h}\right)$, which exhibit good performance, still remains a major challenge. ${ }^{2}$ The key feature of the precise tuning of $V_{t h}$ in GaN-based MISHEMTs is the control of the positive fixed charge $\left(Q_{f}\right)$ at the insulator/III-N interfaces. ${ }^{11}$ The positive $Q_{f}$ was reported for $\mathrm{Al}_{2} \mathrm{O}_{3} /(\mathrm{Al}, \mathrm{Ga}) \mathrm{N},{ }^{12-15} \mathrm{SiO}_{2} / \mathrm{AlGaN}^{15}$ and $\mathrm{SiN} / \mathrm{AlGaN}^{16,17}$ interfaces. Furthermore, it was well demonstrated by many groups that the amount of $Q_{f}$ is often comparable to the negative polarization charge $\left(Q_{\text {pol }}^{-}\right)$at the insulator/III-N interfaces. In spite of that, the nature and location of $Q_{f}$ is still not clear. To get a deep insight into this problem, we performed, in this report, a comprehensive capacitance-voltage $(\mathrm{C}-\mathrm{V})$ characterization of $\mathrm{SiO}_{2} / \mathrm{Al}_{x} \mathrm{Ga}_{1-x} \mathrm{~N} / \mathrm{GaN}$ and $\mathrm{SiN} / \mathrm{Al}_{x} \mathrm{Ga}_{1-x} \mathrm{~N} / \mathrm{GaN}$ metal-insulator-semiconductor (MIS) structures with $\mathrm{Al}$ composition (x) varying in a broad range, from 0.15 to 0.4 . For both structures, we observed a significant $V_{t h}$ shift in C$\mathrm{V}$ curves towards the positive voltage with increasing $\mathrm{x}$. On the contrary, from the comparative measurements performed for the Schottky gate structures, we observed an opposite trend, i.e., the $V_{t h}$ shift towards the negative gate voltage due to increasing $\mathrm{x}$. From the numerical simulations of C-V curves using Poisson's equation supported by the analytical calculations of $V_{t h}$, we showed that $V_{t h}$ shift in the examined MIS structures is due to a marked decrease in the positive $Q_{f}$ with rising x. Finally, we examined the obtained dependencies of $Q_{f}$ vs. x in terms of the different hypotheses proposed in the literature to explain the origin of the positive $Q_{f}$.
In our studies, we used AlGaN/GaN MIS structures, as shown schematically in Fig. 1, which consist of $22 \mathrm{~nm}$ thick $\left(d_{I}\right) \mathrm{SiO}_{2}$ and $\mathrm{SiNx}$ passivation layers and $25 \mathrm{~nm}$ thick $\left(d_{B}\right)$ modulation doped $\mathrm{Al}_{x} \mathrm{Ga}_{1-x} \mathrm{~N}$ barrier layers $(\mathrm{x}=0.15,0.26$, 0.40). We applied plasma-enhanced chemical vapor deposition (PECVD) and electron cyclotron resonance chemical vapor deposition (ECR CVD) techniques for the fabrication of $\mathrm{SiO}_{2}$ and $\mathrm{SiN}$ layers, respectively. All heterojunction samples were cleaned with a HF solution before the insulator deposition in order to mitigate native oxides at the airexposed AlGaN surfaces. Ohmic contacts were ring-shaped $\mathrm{Ti} / \mathrm{Al} / \mathrm{Ti} / \mathrm{Au}$ multilayers, and gate contacts were either $\mathrm{Al} / \mathrm{Au}$ or $\mathrm{Ni} / \mathrm{Au}$ circles with diameters from 200 to $500 \mu \mathrm{m}$. An ohmic annealing was carried out at $830^{\circ} \mathrm{C}$ for $2 \mathrm{~min}$ in $\mathrm{N}_{2}$.

Figure 2 shows the experimental $\mathrm{C}-\mathrm{V}$ curves of the $\mathrm{SiO}_{2} / \mathrm{Al}_{x} \mathrm{Ga}_{1-x} \mathrm{~N} / \mathrm{GaN}$ and $\mathrm{SiN} / \mathrm{Al}_{x} \mathrm{Ga}_{1-x} \mathrm{~N} / \mathrm{GaN}$ structures

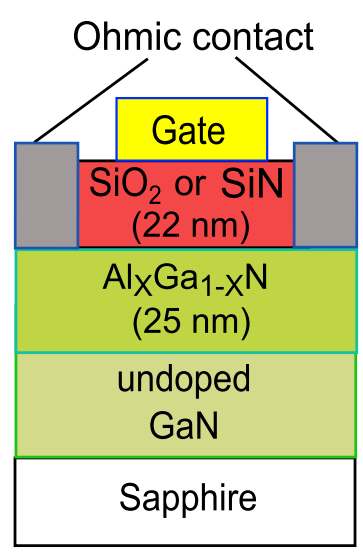

FIG. 1. Scheme of the cross-section of examined AlGaN/GaN MIS structures. 


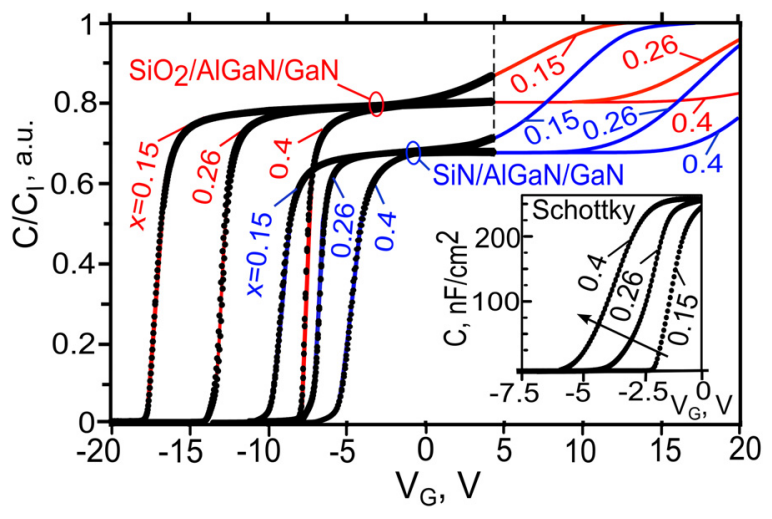

FIG. 2. Experimental (black points limited by the vertical dashed line) and theoretical (solid lines) $\mathrm{C}-\mathrm{V}$ characteristics of the $\mathrm{SiO}_{2} / \mathrm{Al}_{x} \mathrm{Ga}_{1-x} \mathrm{~N} / \mathrm{GaN}$ and $\mathrm{SiN} / \mathrm{Al}_{x} \mathrm{Ga}_{1-x} \mathrm{~N} / \mathrm{GaN}$ structures. In the inset, for comparison, shown measured $\mathrm{C}-\mathrm{V}$ curves of the Schottky gate structures. $C_{I}$ is the insulator capacitance (for $\mathrm{SiO}_{2}, C_{I}=130 \mathrm{nF} / \mathrm{cm}^{2}$, and for $\mathrm{SiN}, C_{I}=240 \mathrm{nF} / \mathrm{cm}^{2}$ ). The solid lines calculated assuming $D_{i t}(E)$ from Figs. 3(b) and 3(c).

obtained at $1 \mathrm{MHz}$ and at RT using an HP4192 impedance analyzer. The bias voltage was changed from $-20 \mathrm{~V}$ to $+4 \mathrm{~V}$ for the $\mathrm{SiO}_{2} / \mathrm{Al}_{x} \mathrm{Ga}_{1-x} \mathrm{~N} / \mathrm{GaN}$ structures and from $-15 \mathrm{~V}$ to $+4 \mathrm{~V}$ for the $\mathrm{SiN}_{2} / \mathrm{Al}_{x} \mathrm{Ga}_{1-x} \mathrm{~N} / \mathrm{GaN}$ structures. In the case of both types of structures, we observed a significant $V_{t h}$ shift in $\mathrm{C}-\mathrm{V}$ curves towards the more positive gate voltage with increasing $x$. In particular, for $\mathrm{SiO}_{2} / \mathrm{Al}_{x} \mathrm{Ga}_{1-x} \mathrm{~N} / \mathrm{GaN}$ structures, an increase of $\mathrm{x}$ from 0.15 to 0.4 caused the $V_{t h}$ shift from -17 to $-7.5 \mathrm{~V}$ and for $\mathrm{SiN} / \mathrm{Al}_{x} \mathrm{Ga}_{1-x} \mathrm{~N} / \mathrm{GaN}$ structures from -9.5 to $-5 \mathrm{~V}$. Due to such a large shift, we could observe typical of MISH structures two-step C-V curves ${ }^{2,3,18}$ only in the case of $\mathrm{x}=0.15$. In addition, for comparison, in the inset of Fig. 2, we also present the results of $\mathrm{C}-\mathrm{V}$

(a)

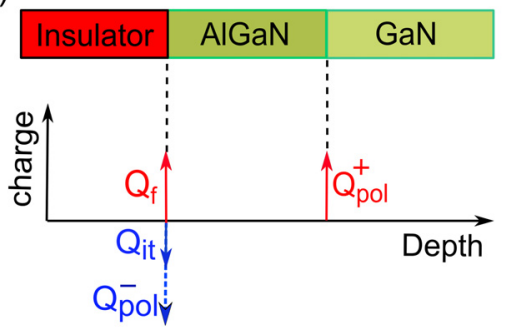

$\begin{array}{ll}\text { (b) } \mathrm{SiO}_{2} / \mathrm{Al}_{x} \mathrm{Ga}_{1-x} \mathrm{~N} / \mathrm{GaN} & \text { (c) } \mathrm{SiN} / \mathrm{Al}_{x} \mathrm{Ga}_{1-x} \mathrm{~N} / \mathrm{GaN}\end{array}$

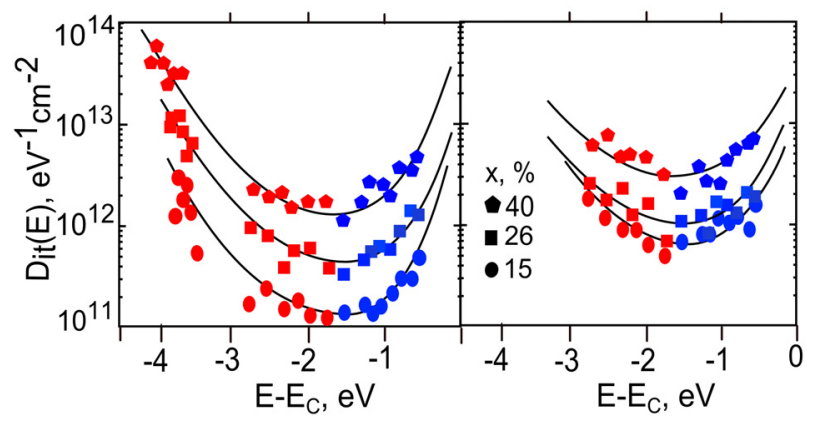

FIG. 3. Scheme of the charge distribution in AlGaN/GaN MIS structures (a), $D_{i t}(E)$ at $\mathrm{SiO}_{2} / \mathrm{Al}_{x} \mathrm{Ga}_{1-x} \mathrm{~N}$ interfaces (Ref. 15) (b) and $D_{i t}(E)$ at $\mathrm{SiN} /$ $\mathrm{Al}_{x} \mathrm{Ga}_{1-x} \mathrm{~N}$ interfaces (c) used in the calculations of $\mathrm{C}-\mathrm{V}$ curves. In the case of $\mathrm{SiO}_{2} / \mathrm{Al}_{x} \mathrm{Ga}_{1-x} \mathrm{~N}, Q_{i t}^{f r}$ (in $\mathrm{C} / \mathrm{m}^{2}$ ) is $2.1 \times 10^{-4}, 6.3 \times 10^{-4}$, and $2 \times 10^{-3}$ for $\mathrm{x}=0.15,0.26$, and 0.4 , respectively, and in the case of $\mathrm{SiN} / \mathrm{Al}_{x} \mathrm{Ga}_{1-x} \mathrm{~N}$, $Q_{i t}^{f r}\left(\right.$ in $\left.\mathrm{C} / \mathrm{m}^{2}\right)$ is $1.1 \times 10^{-3}, 1.9 \times 10^{-3}$, and $4.8 \times 10^{-3}$ for $\mathrm{x}=0.15,0.26$, and 0.4 , respectively.
TABLE I. The values of $Q_{p o l}^{+}$and $Q_{p o l}^{-}$used in calculations.

\begin{tabular}{lcc}
\hline \hline $\mathrm{x}$ & $Q_{\text {pol }}^{+}\left(\mathrm{C} / \mathrm{m}^{2}\right)$ & $Q_{\text {pol }}^{-}\left(\mathrm{C} / \mathrm{m}^{2}\right)$ \\
\hline 0.15 & 0.015 & -0.035 \\
0.26 & 0.022 & -0.044 \\
0.4 & 0.035 & -0.06 \\
\hline \hline
\end{tabular}

measurements for the Schottky gate structures. One can note that $V_{t h}$ in this case exhibits an opposite behavior, i.e., the shift towards the more negative gate voltage with increasing $\mathrm{x}$.

In order to explain the above results, we carried out the theoretical calculations of $\mathrm{C}-\mathrm{V}$ curves based on solving a Poisson's equation. The details of calculations can be found in Refs. 15 and 19. In the calculations, we took into account the following charges, shown schematically in Fig. 3(a): (i) net positive polarization charge $\left(Q_{\text {pol }}^{+}\right)$at the $\mathrm{AlGaN} / \mathrm{GaN}$ interface originating from the spontaneous polarization of $\mathrm{AlGaN}$ and $\mathrm{GaN}$ as well as piezoelectric polarization of $\mathrm{AlGaN}$, (ii) interface state charge $\left(Q_{i t}\right)$ at the insulator/ AlGaN interface related to the interface state density distribution $\left(D_{i t}(E)\right)$ and (iii) net fixed charge $\left(Q_{\text {fnet }}\right)$ at the insulator/AlGaN interface, which includes $Q_{f}$ and the negative polarization charge, $Q_{p o l}^{-}$, originating from the spontaneous and piezoelectric polarization of $\mathrm{AlGaN}$. We did not take into account the bulk charge in $\mathrm{SiO}_{2}$ because we showed recently ${ }^{15}$ from the photo-assisted $\mathrm{C}-\mathrm{V}$ measurements that this charge can be negligible in the case of the investigated structures. In addition, based on our recent studies of the surface photovoltage effect, ${ }^{20}$ we also neglected the bulk charge in $\mathrm{SiN}$. It was possible because in the case of the $\mathrm{SiN} / \mathrm{GaN}$ structure, we observed a very fast recovery time of the surface photovoltage after turn-off of the ultraviolet light, which indicated the lack of the charge trapping effects in the SiN bulk. The values of $Q_{p o l}^{+}$and $Q_{p o l}^{-}$for different x were taken from Ref. 21 and summarized in Table I. Furthermore, in the calculations, we assumed that the metal barrier height $\left(\phi_{b}\right)$ for $\mathrm{Al} / \mathrm{SiO}_{2}$ and $\mathrm{Al} / \mathrm{SiN}$ was $3.7 \mathrm{eV}$ (Ref. 22) and $2 \mathrm{eV} 2 \mathrm{eV}$ (Ref. 22), respectively. The other parameters used in the calculations, i.e., the conduction band (CB) off-sets for the insulator/ $/ \mathrm{Al}_{x} \mathrm{Ga}_{1-x} \mathrm{~N}$ junction $\left[\Delta E_{C 1}(\mathrm{x})\right]$ and $\mathrm{Al}_{x} \mathrm{Ga}_{1-x} \mathrm{~N} / \mathrm{GaN}\left[\Delta E_{C 2}(x)\right]$ are listed in Tables II and III, respectively. The value of $\Delta E_{C 1}(x)$ was estimated from the following relationship: ${ }^{22} \Delta E_{C 1}(x)=\Delta E_{C 3}-$ $\Delta E_{C 2}(x)$, where $\Delta E_{C 3}$ is the conduction-band off-set for the insulator/GaN junction $\left[\Delta E_{C 3}\right.$ for $\mathrm{SiO}_{2} / \mathrm{GaN}$ is $3.6 \mathrm{eV}$ (Ref. 22) and for $\mathrm{SiN} / \mathrm{GaN}$ is $1.2 \mathrm{eV}$ (Ref. 22)].

The solutions were obtained with: (i) Neumann type boundary conditions at the insulator/AlGaN and AlGaN/

TABLE II. Conduction band off-sets, $\Delta E_{C 1}(\mathrm{x})$, at insulator/ $\mathrm{Al}_{x} \mathrm{Ga}_{1-x} \mathrm{~N}$ interfaces.

\begin{tabular}{lc}
\hline \hline Interface & $\Delta E_{\mathrm{Cl}}(\mathrm{x})(\mathrm{eV})$ \\
\hline $\mathrm{SiO}_{2} / \mathrm{Al}_{0.15} \mathrm{Ga}_{0.85} \mathrm{~N}$ & 3.28 \\
$\mathrm{SiO}_{2} / \mathrm{Al}_{0.26} \mathrm{Ga}_{0.74} \mathrm{~N}$ & 3.11 \\
$\mathrm{SiO}_{2} / \mathrm{Al}_{0.4} \mathrm{Ga}_{0.6} \mathrm{~N}$ & 2.88 \\
$\mathrm{SiN} / \mathrm{Al}_{0.15} \mathrm{Ga}_{0.85} \mathrm{~N}$ & 0.87 \\
$\mathrm{SiN} / \mathrm{Al}_{0.26} \mathrm{Ga}_{0.74} \mathrm{~N}$ & 0.72 \\
$\mathrm{SiN} / \mathrm{Al}_{0.4} \mathrm{Ga}_{0.6} \mathrm{~N}$ & 0.48 \\
\hline \hline
\end{tabular}


TABLE III. Conduction band off-sets, $\Delta E_{C 2}(x)$, at $\mathrm{Al}_{x} \mathrm{Ga}_{1-x} \mathrm{~N} / \mathrm{GaN}$ interfaces. $^{21}$

\begin{tabular}{lc}
\hline \hline Interface & $\Delta E_{\mathrm{C} 2}(\mathrm{x})(\mathrm{eV})$ \\
\hline $\mathrm{Al}_{0.15} \mathrm{Ga}_{0.85} \mathrm{~N} / \mathrm{GaN}$ & 0.32 \\
$\mathrm{Al}_{0.26} \mathrm{Ga}_{0.74} \mathrm{~N} / \mathrm{GaN}$ & 0.48 \\
$\mathrm{Al}_{0.4} \mathrm{Ga}_{0.6} \mathrm{~N} / \mathrm{GaN}$ & 0.72 \\
\hline \hline
\end{tabular}

GaN interfaces and (ii) Dirichlet type boundary conditions at the contacts. In particular, the boundary conditions at the insulator/AlGaN interface are expressed as

$$
\epsilon_{0} \epsilon_{B} E_{B}-\epsilon_{0} \epsilon_{I} E_{I}=Q_{i t}+Q_{f n e t},
$$

where $E_{B}$ and $E_{I}$ is the electric field intensity in $\mathrm{AlGaN}$ and insulator, respectively, $\epsilon_{B}$ and $\epsilon_{I}$ is the relative $\mathrm{AlGaN}$ and insulator permittivity, respectively $\left(\epsilon_{B}=10.3\right.$, for $\mathrm{SiO}_{2}$ $\epsilon_{I}=3.9$ and for $\operatorname{SiN} \epsilon_{I}=7$ ); $Q_{i t}$ can be expressed as follows:

$$
Q_{i t}=q \int_{E_{V}}^{E_{C N L}} D_{i t}(E)\left(1-f_{i t}\right) d E-q \int_{E_{C N L}}^{E_{C}} D_{i t}(E) f_{i t} d E
$$

where $E_{V}$ and $E_{C}$ are the top of the valence band (VB) and bottom of the conduction band $(\mathrm{CB})$, respectively, $E_{C N L}$ is the charge neutrality level, and $f_{i t}$ is the Fermi-Dirac function. In the calculations, we used $D_{i t}(E)$ at $\mathrm{SiO}_{2} / \mathrm{Al}_{x} \mathrm{Ga}_{1-x} \mathrm{~N}$ interfaces from our recent paper ${ }^{15}$ [shown in Fig. 3(b)]. In the case of $\mathrm{SiN} / \mathrm{Al}_{x} \mathrm{Ga}_{1-x} \mathrm{~N}$ interfaces, $D_{i t}(E)$ was determined from the photo-assisted $\mathrm{C}-\mathrm{V}$ method mon $^{3,15}$ and then summarized in Fig. 3(c). The details of the measurements can be found in Refs. 2, 3, and 15. As a light source, we used a xenon lamp and a set of band-pass filters (the passing photon energy: $1.26 \mathrm{eV}<h v<3 \mathrm{eV}$ ). During the calculations of C$\mathrm{V}$ curves, we assumed that $Q_{i t}$ cannot follow the fast ac voltage signal but can follow the slow gate voltage sweep (highfrequency measurement).

While the shift of $V_{t h}$ in the Schottky structures towards the negative gate voltage with increasing $x$ (Fig. 2) is obviously due to an increase of the positive $Q_{\text {pol }}^{+}$, the shift of $V_{t h}$ in MIS AlGaN/GaN structures towards the positive voltage with x can be due to either an increase of the negative $Q_{\text {pol }}^{-}$ and $Q_{i t}$ or/and a decrease of the positive $Q_{f}$. Therefore, to determine which of these factors can be responsible for the $V_{t h}$ shift, first we calculated the $\mathrm{C}-\mathrm{V}$ curves for the $\mathrm{SiO}_{2} /$ $\mathrm{Al}_{x} \mathrm{Ga}_{1-x} \mathrm{~N} / \mathrm{GaN}$ and $\mathrm{SiN} / \mathrm{Al}_{x} \mathrm{Ga}_{1-x} \mathrm{~N} / \mathrm{GaN}$ structures with $\mathrm{x}=0.15$ and 0.40 , assuming, for both $\mathrm{x}$, the same $Q_{f}$ value equal to $\left|Q_{\text {pol }}^{-}\right|$for $\mathrm{x}=0.15$ (see Table I). Such an approach allowed to examine, if the solely variations of $Q_{\text {pol }}^{-}$and $Q_{i t}$ vs. $x$ can have the stronger impact on $V_{t h}$ than increasing of the positive polarization charge $Q_{\text {pol }}^{+}$and thus, in consequence, if they can induce the $V_{t h}$ shift towards the positive gate voltage. The results of the $V_{t h}$ calculations are summarized in Fig. 4(a). It is evident from this figure that the $\mathrm{C}-\mathrm{V}$ curves are shifted with increasing $\mathrm{x}$ towards the more negative voltage. This means that in order to induce the $V_{t h}$ shift towards the positive bias (Fig. 2), the significant reduction of the positive $Q_{f}$ vs. x is necessary. From the fitting of the experimental C-V curves by the theoretical ones (Fig. 2), we estimated exactly the values of $Q_{f}$ at $\mathrm{SiO}_{2} / \mathrm{Al}_{x} \mathrm{Ga}_{1-x} \mathrm{~N}$ and

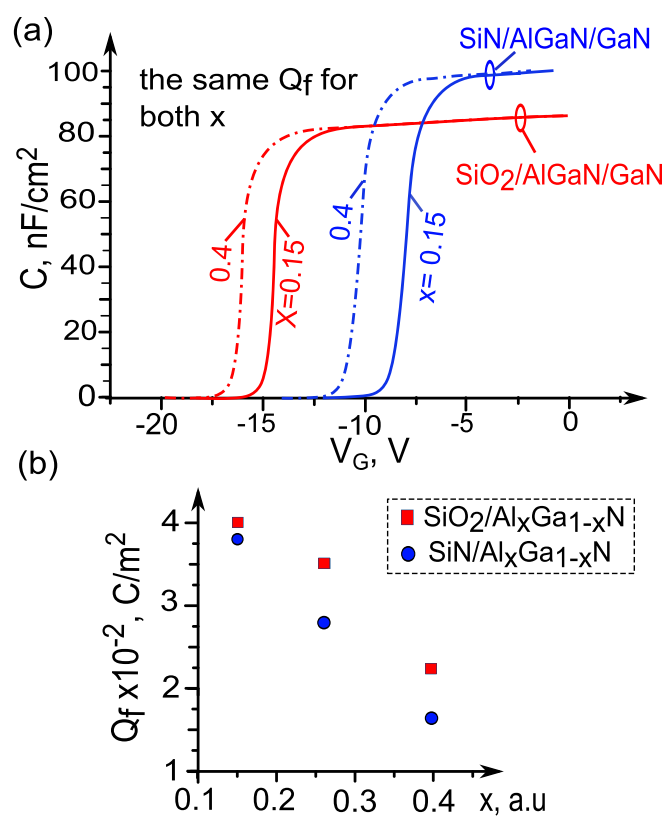

FIG. 4. C-V characteristics of the $\mathrm{SiO}_{2} / \mathrm{Al}_{x} \mathrm{Ga}_{1-x} \mathrm{~N} / \mathrm{GaN}$ and $\mathrm{SiN} / \mathrm{Al}_{x} \mathrm{Ga}_{1-x} \mathrm{~N} /$ $\mathrm{GaN}$ structures with $\mathrm{x}=0.15$ and 0.4 calculated assuming, for both $\mathrm{x}$, the same $Q_{f}$ value equal to $\left|Q_{p o l}^{-}\right|$for $\mathrm{x}=0.15$ (see Table I) and $d_{B}=d_{I}=30 \mathrm{~nm}$ (a); dependencies of $Q_{f}$ vs. x, determined from fitting of the experimental CV curves (see Fig. 2) (b).

$\mathrm{SiN} / \mathrm{Al}_{x} \mathrm{Ga}_{1-x} \mathrm{~N}$ interfaces and summarized them in Fig. 4(b) and Table IV. We found that in the case of $\mathrm{SiO}_{2} / \mathrm{Al}_{x} \mathrm{Ga}_{1-x} \mathrm{~N} /$ $\mathrm{GaN}$, an increase of $\mathrm{x}$ from 0.15 to 0.4 caused reducing $Q_{f}$ from 0.04 to $0.022 \mathrm{C} / \mathrm{m}^{2}$ and in the case of $\mathrm{SiN} / \mathrm{Al}_{x} \mathrm{Ga}_{1-x} \mathrm{~N} /$ $\mathrm{GaN}$, from 0.038 to $0.016 \mathrm{C} / \mathrm{m}^{2}$. In addition, it should be noted that the theoretical calculations of $\mathrm{C}-\mathrm{V}$ curves for the examined structures with $\mathrm{x}=0.26$ and 0.4 indicate that the second step at these curves should occur much beyond the measured gate voltage range (see Fig. 2). This confirms that the lack of observation of the second step of $\mathrm{C}-\mathrm{V}$ curves for these structures is due to the large shift of $\mathrm{C}-\mathrm{V}$ curves towards the positive gate voltage with $\mathrm{x}$ but not due to high $D_{i t}(E)$. Moreover, as one can note from Fig. 2, the second step of $\mathrm{C}-\mathrm{V}$ curves in the case of the structures with $\mathrm{X}=0.15$, was well reproduced using $D_{i t}(E)$ from Figs. 3(b) and 3(c). This gives an additional independent support for $D_{i t}(E)$ determined from the photo-assisted C-V method.

It should be stressed that the values of $Q_{f}$ obtained from the simulations of $\mathrm{C}-\mathrm{V}$ curves can be confirmed through the analytical calculations of $V_{t h}$ using the model proposed by Tapajna and Kuzmik ${ }^{23}$ Namely, within this model, $V_{t h}$ can be expressed as follows:

TABLE IV. The values of $Q_{f}$ determined (a) from C-V fitting (Fig. 2) and (b) from Eq. (4).

\begin{tabular}{lcc}
\hline \hline Interface & (a) $Q_{\mathrm{f}} \times 10^{-2}\left(\mathrm{C} / \mathrm{m}^{2}\right)$ & (b) $Q_{\mathrm{f}} \times 10^{-2}\left(\mathrm{C} / \mathrm{m}^{2}\right)$ \\
\hline $\mathrm{SiO}_{2} / \mathrm{Al}_{0.15} \mathrm{Ga}_{0.85} \mathrm{~N}$ & 4.05 & 4.08 \\
$\mathrm{SiO}_{2} / \mathrm{Al}_{0.26} \mathrm{Ga}_{0.74} \mathrm{~N}$ & 3.52 & 3.56 \\
$\mathrm{SiO}_{2} / \mathrm{Al}_{0.4} \mathrm{Ga}_{0.6} \mathrm{~N}$ & 2.17 & 2.20 \\
$\mathrm{SiN} / \mathrm{Al}_{0.15} \mathrm{Ga}_{0.85} \mathrm{~N}$ & 3.77 & 3.79 \\
$\mathrm{SiN} / \mathrm{Al}_{0.26} \mathrm{Ga}_{0.74} \mathrm{~N}$ & 2.76 & 2.81 \\
$\mathrm{SiN} / \mathrm{Al}_{0.4} \mathrm{Ga}_{0.6} \mathrm{~N}$ & 1.65 & 1.62 \\
\hline \hline
\end{tabular}




$$
\begin{aligned}
V_{t h}= & \frac{\phi_{b}}{q}-\frac{\Delta E_{C}}{q}-\frac{\phi_{f}}{q}-\frac{d_{I}}{\epsilon_{I}}\left(Q_{p o l}-\right) \\
& -\frac{d_{I} \epsilon_{B}+d_{B} \epsilon_{I}}{\epsilon_{I} \epsilon_{B}}\left(Q_{p o l}{ }^{+}\right)-\frac{d_{I}}{\epsilon_{I}}\left(Q_{f}+Q_{i t}^{f r}+Q_{I}^{b u l k}\right),
\end{aligned}
$$

where $\phi_{f}$ is the Fermi potential in the GaN bulk $(\sim 0.2 \mathrm{eV})$, $Q_{I}^{\text {bulk }}$ is the insulator bulk charge, and $Q_{i t}^{f r}$ is the charge corresponding to the "frozen" interface states ${ }^{3}$ between $E_{C N L}$ and $0.8 \mathrm{eV}$ from $E_{C}\left(Q_{i t}^{f r} \approx-q \int_{E_{C N L}}^{0.8 e V} D_{i t}(E) d E\right)$. The values of $Q_{i t}^{f r}$ are given in the caption of Fig. 3 .

For our structures, $Q_{I}^{\text {bulk }}$ can be neglected (as mentioned before); therefore, from Eq. (3), we can estimate $Q_{f}$ as follows:

$$
\begin{aligned}
Q_{f} \approx & \frac{\epsilon_{I}}{d_{I}}\left(\frac{\phi_{b}}{q}-\frac{\Delta E_{C}}{q}-\frac{\phi_{f}}{q}-V_{t h}\right)-\left(Q_{p o l}^{-}\right) \\
& -\frac{d_{I} \epsilon_{B}+d_{B} \epsilon_{I}}{d_{I} \epsilon_{B}}\left(Q_{p o l}^{+}\right)-Q_{i t}^{f r} .
\end{aligned}
$$

After substituting into Eq. (4) the values from Tables I to III as well as the values of $Q_{i t}^{f r}$ (see the caption of Fig. 3) and $V_{t h}$, we calculated $Q_{f}$, as shown in Table IV. It is clear from this table that we obtained a good agreement with the values determined from the fitting of $\mathrm{C}-\mathrm{V}$ curves.

In order to understand the obtained dependencies of $Q_{f}$ vs. x [Fig. 4(b)], we examined the different hypotheses proposed in the literature to explain the origin of the positive $Q_{f}$ at the insulator/III-N interfaces, which are schematically illustrated in Fig. 5. At first, we considered the hypothesis developed by Ganguly et al., ${ }^{12}$ denoted here as hypothesis A. According to this hypothesis, $Q_{f}$ is related to the Al-O bonds at the interface. On the other hand, it should be noted that it was observed experimentally that the density of Al-O bonds at the AlGaN surface increases with $x$ due to the enhancement of the chemical affinity of aluminum to oxygen. ${ }^{24}$ Therefore, from hypothesis A it follows that one should expect an increase of $Q_{f}$ vs. x, which is in contradiction with our observation. Another hypothesis, introduced by Hayashi et al. $^{25}$ and Tapajna and Kuzmik ${ }^{23}$ (hypothesis B) suggests that $Q_{f}$ is linked to the ionized donor-like surface defects formed during the growth on the III-N heterostructure. Furthermore, it was shown by Gordon et al. ${ }^{26}$ that the concentration of donor-like surface defects increases with

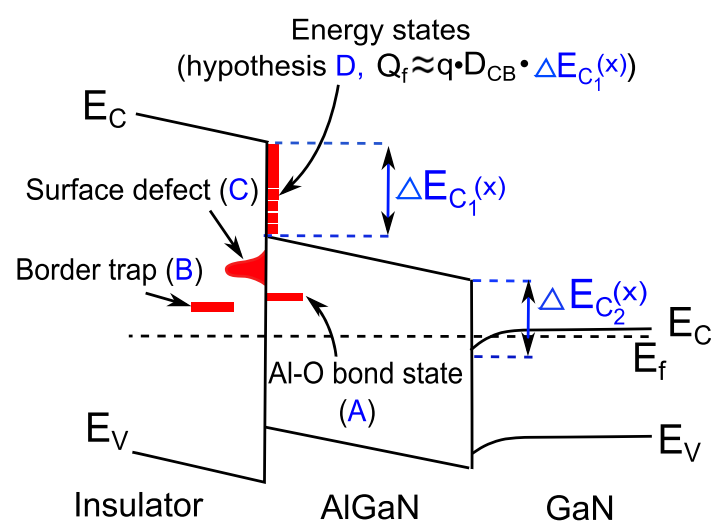

FIG. 5. Schematic illustration of the hypotheses ${ }^{12,13,17,23,25}$ (A-D) proposed to explain the origin of the positive $Q_{f}$ at the insulator/III-N interfaces. increasing $\mathrm{x}$; thus within hypothesis $\mathrm{B}$, one should also observe, contrary to our results, an enlargement of $Q_{f}$ vs. x. The next hypothesis, developed by Bakeroot et al. ${ }^{17}$ (hypothesis C), assigned $Q_{f}$ to the gate insulator border trap. Concerning this hypothesis, one should consider two cases: (i) when the border trap responsible for $Q_{f}$ is located close to the insulator/AlGaN interface inside the disordered interface region, and (ii) when the border trap is located far from the interface. In the case $(i)$, the border trap density $\left(D_{B T}\right)$ should increase with $\mathrm{x}$ like $D_{i t}(E)$ at the $\mathrm{SiO}_{2} / \mathrm{AlGaN}$ and $\mathrm{SiN} /$ AlGaN interfaces [Figs. 3(b) and 3(c)]. On the contrary, in the case $(i i), D_{B T}$ should depend weakly on $\mathrm{x}$. Therefore, according to hypothesis $\mathrm{C}, Q_{f}$ can increase or can be rather independent on $\mathrm{x}$, against to our finding. The last hypothesis proposed by Esposto et al. ${ }^{13}$ (hypothesis D), postulates that $Q_{f}$ originates from the energy states between CB bottom of the AlGaN and insulator layer. Only this hypothesis is able to explain the observed variations of $Q_{f}$ vs. x. Namely, if we assume the continuous distribution of the above states, then it is evident that $Q_{f}$ can be approximately expressed by the following relationship (see Fig. 5):

$$
Q_{f} \approx q D_{C B} \Delta E_{C 1}(x),
$$

where $D_{C B}$ is the average density of states between the edge of $\mathrm{CB}$ of an insulator and $\mathrm{AlGaN}$.

Because $\Delta E_{C 1}(x)$ at the $\mathrm{SiO}_{2} / \mathrm{Al}_{x} \mathrm{Ga}_{1-x} \mathrm{~N}$ and $\mathrm{SiN} /$ $\mathrm{Al}_{x} \mathrm{Ga}_{1-x} \mathrm{~N}$ interfaces decreases with increasing $\mathrm{x}$ (see Table II), thus from Eq. (5), it follows that $Q_{f}$ should also decrease with $\mathrm{x}$. Moreover, the independent support for the hypothesis $\mathrm{D}$ comes from our recent studies based on the photo-assisted C-V measurements. ${ }^{15}$ Namely, we showed that the states between $\mathrm{CB}$ of $\mathrm{SiO}_{2}$ and $\mathrm{AlGaN}$ can be fully ionized and thus they can behave like the fixed charge.

Finally, it is worth to highlight the important finding of our work that $Q_{f}$ can be precisely controlled by the barrier composition [as in Fig. 4(b)]. In particular, Figs. 2 and 4(b) suggest that by using an appropriate high $\mathrm{x}$, in the case of $\mathrm{SiO}_{2} / \mathrm{AlGaN} / \mathrm{GaN}$ and $\mathrm{SiN} / \mathrm{AlGaN} / \mathrm{GaN}$ structures, one can obtain a reduced $Q_{f}$ to the negligible value and, as a result, shifting $V_{t h}$ to the region of the positive gate voltage, which ensures normally off operation. ${ }^{2}$

In conclusion, we found that the positive fixed charge $Q_{f}$ at the insulator $/ \mathrm{Al}_{x} \mathrm{Ga}_{1-x} \mathrm{~N}$ interfaces exhibits a significant decrease with increasing $\mathrm{x}$, which results in the $V_{\text {th }}$ shift towards the positive gate voltage. We examined this result with respect to the various hypotheses developed in the literature to explain the origin of the positive $Q_{f}$ at insulator/III$\mathrm{N}$ interfaces. We showed that the hypothesis proposing that $Q_{f}$ originates from the energy states between the CB bottom of an insulator and $\mathrm{AlGaN}$ is the most suitable for the explanation of our data. We believe that the revealed dependence of $Q_{f}$ on x can be useful for the tuning $V_{t h}$ in $\mathrm{AlGaN} / \mathrm{GaN}$ MISHEMTs.

One of the authors, M.M., thanks RCIQE, Hokkaido University, Sapporo (Japan), for the postdoctoral fellowship. The authors' gratitude is also addressed to Professor Tamotsu Hashizume for his generous support and valuable discussions and to Mr. Kenya Nishiguchi for his contribution 
to the calculations. The work was realized within the SAFEMOST project, Visegrad Group (V4)_Japan Joint Research Program on Advanced Materials (in Poland, the NCRD Project, No. 14/990/PNN16/0072).

${ }^{1}$ U. K. Mishra, L. Shen, T. E. Kazior, and Y. F. Wu, Proc. IEEE 96, 287 (2008).

${ }^{2}$ Z. Yatabe, J. Asubar, and T. Hashizume, J. Phys. D: Appl. Phys. 49, 393001 (2016).

${ }^{3}$ C. Mizue, Y. Hori, M. Miczek, and T. Hashizume, Jpn. J. Appl. Phys., Part 1 50, 021001 (2011).

${ }^{4}$ I. Rossetto, D. Bisi, C. de Santi, A. Stocco, and G. Meneghesso, in Power GaN Devices, edited by M. Meneghini, G. Meneghesso, and E. Zanoni (Springer, 2017), pp. 197-236.

${ }^{5}$ G. Meneghesso, M. Meneghini, I. Rossetto, D. Bisi, S. Stoffels, M. Van Hove, S. Decoutere, and E. Zanoni, Semicond. Sci. Technol. 31, 093004 (2016).

${ }^{6}$ M. Kanamura, T. Ohki, T. Kikkawa, K. Imanishi, T. Imada, A. Yamada, and N. Hara, IEEE Electron Device Lett. 31, 189 (2010).

${ }^{7}$ K. Shinohara, D. Regan, Y. Tang, A. Corrion, D. Brown, J. Wong, J. Robinson, H. Fung, A. Schmitz, T. Oh, S. Kim, P. Chen, R. Nagele, A. Margomenos, and M. Micovic, IEEE Trans. Electron Devices 60, 2982 (2013).

${ }^{8}$ D. S. Lee, Z. Liu, and T. Palacios, Jpn. J. Appl. Phys. 53, 100212 (2014).

${ }^{9}$ T. Ueda, M. Ishida, T. Tanaka, and D. Ueda, Jpn. J. Appl. Phys. 53, 100214 (2014)

${ }^{10}$ M. Wang, Y. Wang, C. Zhang, B. Xie, C. P. Wen, J. Wang, Y. Hao, W. Wu, K. J. Chen, and B. Shen, IEEE Trans Electron Devices 61, 2035 (2014).

${ }^{11}$ Y. Zhang, M. Sun, S. J. Joglekar, T. Fujishima, and T. Palacios, Appl. Phys. Lett. 103, 033524 (2013).
${ }^{12}$ S. Ganguly, J. Verma, G. W. Li, T. Zimmermann, H. L. Xing, and D. Jena, Appl. Phys. Lett. 99, 193504 (2011).

${ }^{13}$ M. Esposto, S. Krishnamoorthy, D. N. Nath, S. Bajaj, T. H. Hung, and S. Rajan, Appl. Phys. Lett. 99, 133503 (2011).

${ }^{14}$ J. Son, V. Chobpattana, B. M. McSkimming, and S. Stemmer, Appl. Phys, Lett. 101, 102905 (2012).

${ }^{15}$ M. Matys, B. Adamowicz, A. Domanowska, A. Michalewicz, R. Stoklas, M. Akazawa, Z. Yatabe, and T. Hashizume, J. Appl. Phys. 120, 225305 (2016).

${ }^{16}$ M. Capriotti, A. Alexewicz, C. Fleury, M. Gavagnin, O. Bethge, D. Visalli, J. Derluyn, H. D. Wanzenbock, E. Bertagnolli, D. Pogany, and G. Strasser, Appl. Phys. Lett. 104, 113502 (2014).

${ }^{17}$ B. Bakeroot, S. You, T.-L. Wu, J. Hu, M. Van Hove, B. De Jaeger, K. Geens, S. Stoffels, and S. Decoutere, Appl. Phys. 116, 134506 (2014).

${ }^{18}$ S. Huang, S. Yang, J. Roberts, and K. J. Chen, Jpn. J. Appl. Phys. Part 1 50, 110202 (2011).

${ }^{19}$ M. Miczek, C. Mizue, T. Hashizume, and B. Adamowicz, J. Appl. Phys. 103, 104510 (2008)

${ }^{20}$ M. Matys, B. Adamowicz, Z. R. Zytkiewicz, A. Taube, R. Kruszka, and A. Piotrowska, Appl. Phys. Lett. 109, 051106 (2016).

${ }^{21}$ O. Ambacher, J. Smart, J. R. Shealy, N. G. Weimann, K. Chu, M. Murphy, W. J. Schaff, and L. F. Eastman, J. Appl. Phys. 85, 3222 (1999).

${ }^{22}$ N. Maeda, M. Hiroki, N. Watanabe, Y. Oda, H. Yokoyama, T. Yagi, T. Makimoto, T. Enoki, and T. Kobayashi, Jpn. J. Appl. Phys., Part 1 46, 547 (2007).

${ }^{23}$ M. Tapajna and J. Kuzmik, Appl. Phys. Lett. 100, 113509 (2012).

${ }^{24}$ H. Yang, X. Zhanga, S. Wang, M. Zhu, and Y. Cui, Eur. Phys. J. Appl. Phys. 72, 20301 (2015).

${ }^{25}$ Y. Hayashi, S. Sugiura, S. Kishimoto, and T. Mizutani, Solid-State Electron. 54, 1367 (2010).

${ }^{26}$ L. Gordon, M.-S. Miao, S. Chowdhury, M. Higashiwaki, U. K. Mishra, and C. G. Van de Walle, J. Phys. D: Appl. Phys. 43, 505501 (2010). 